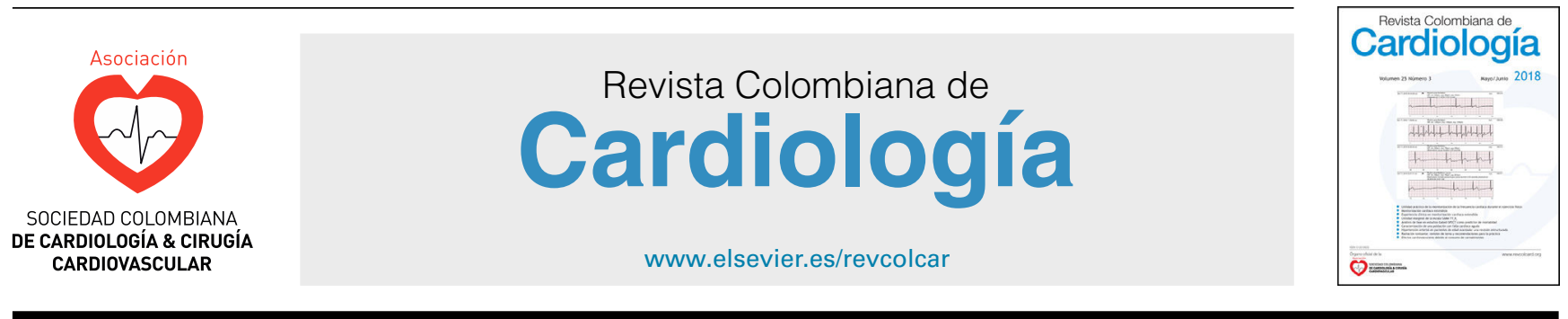

\title{
Presentación
}

\section{Darío Echeverri}

Editor Jefe, Revista Colombiana de Cardiología

En nombre de la Asociación Sociedad Colombiana de Cardiología y Cirugía Cardiovascular y su órgano oficinal, la Revista Colombiana de Cardiología, hacemos un reconocimiento al Colegio Colombiano de Hemodinamia e Intervencionismo Cardiovascular por la iniciativa de realizar el actual Suplemento de Radioprotección, y, así mismo, a todos los distinguidos autores de los diferentes capítulos que lo conforman, por el gran esfuerzo en el logro de este número extraordinario conformado por diferentes tópicos, tratados con gran solvencia y calidad científica.

El físico alemán Wilhelm Conrad Röntgen descubrió los rayos $X$ en 1895, mientras experimentaba con los tubos de Hittorff-Crookes y la bobina de Ruhmkorff para investigar la fluorescencia violeta que producían los rayos catódicos. Este descubrimiento fue ampliamente reconocido, incluso con el Premio Nobel de Física en 1901 por el descubrimiento de los rayos Röntgen o, como le agradaría a su descubridor que los llamáramos, rayos X. Entre 1901 y 1936, cinco premios Nobel fueron relacionados con los rayos $X$, hecho con el que se reflejó la importancia de este descubrimiento para la ciencia. Desde entonces, los rayos $X$ y la radiación han acompañado a la medicina con fines diagnósticos y terapéuticos de múltiples condiciones.

Con la utilización adecuada de los rayos $X$ es posible encontrar la ubicación exacta de un problema y hacer el diagnóstico mediante un enfoque lógico que permita comprender la imagen. Pese a los grandes avances en la tecnología, con disponibilidad de dosis pulsada, filtros, colimadores y software, las diferentes técnicas ofrecen exposición de rayos $\mathrm{X}$ tanto a pacientes como al personal expuesto. El objetivo de las normas de protección radiológica es hacer que el lugar de trabajo donde se utiliza radiación sea tan seguro como sea humanamente posible. La evolución gradual en los últimos veinte años ha sido hacia una definición más precisa de los límites de exposición ocupacional. Estos se han creado no solo en términos de efectos a corto plazo, sino también en términos de riesgos a largo plazo que involucran problemas como el potencial de carcinogénesis y cambios genéticos.

Se requiere que la comunidad de usuarios de la radiación realice sus procedimientos de forma que el valor absoluto de la dosis equivalente del individuo en REM (del inglés Röntgen equivalent man) no exceda su edad en años. Debería haber límites adicionales para tejidos y órganos basados en los efectos a corto plazo. Por tanto, los órganos individuales están limitados a dosis equivalentes lo suficientemente bajas como para garantizar que no se excedan los valores umbral de dosis.

De estas consideraciones básicas ha surgido el concepto de "tan bajo como sea razonablemente posible" (ALARA). Todos los límites de dosis en la protección contra la radiación están sujetos a dicho concepto, aunque se reconoce que los comités de establecimiento de normas básicamente preferirían recomendaciones que permitan una exposición cero del personal. Estos datos generales y muchos más de trasfondo son de gran importancia para reconocer todo el problema respecto a la exposición a la radiación y sus potenciales efectos a corto y largo plazo, así como los posibles mecanismos por los cuales la exposición a la radiación se puede controlar y limitar al mayor grado posible.

Este documento intenta brindar información sólida y reciente en el trascendental campo de exposición a la radiación en el humano. Además de la exposición a la radiación natural, se hace especial hincapié en la exposición a la radiación ocupacional y los riesgos relacionados.

Expresamos nuestro agradecimiento sincero a los autores que han contribuido gentilmente en esta edición, por todo su esfuerzo y tiempo invertido. 